Measur ement s of sel $f-f i$ el $d$ and vol tage for the REBCO st acked t apes assenbl ed i $\mathrm{n}$ ri gi d st ruct ure (STARS) conduct or at $77 \mathrm{~K}$

\begin{tabular}{|l|l|}
\hline $\begin{array}{l}\text { jour nal or } \\
\text { publ i cat i on } \mathrm{titl} \text { e }\end{array}$ & Cryogeni cs \\
\hline vol une & 115 \\
\hline page range & 103278 \\
\hline year & $2021-$ O4 \\
\hline URL & ht t p: //hdl . handl e. net /10655/00012964 \\
\hline
\end{tabular}




\title{
Measurements of self-field and voltage for the REBCO stacked tapes assembled in rigid structure (STARS) conductor at $77 \mathrm{~K}$
}

\author{
T. Obana, N. Yanagi
}

National Institute for Fusion Science, 322-6 Oroshi, Toki, Gifu, 509-5292, Japan

*Corresponding author. Tel.: +81572582137 ; fax: +81572582616

E-mail address: obana.tetsuhiro@nifs.ac.jp (T. Obana)

\begin{abstract}
The measurements of self-fields and voltages for the stacked tapes assembled in rigid structure (STARS) conductor were carried out when the conductor immersed in liquid nitrogen was energized. In the measurements, a $3 \mathrm{~m}$ straight line shaped STARS conductor, which is composed of 45 REBCO tapes (15 tapes $\times 3$ rows) embedded in a copper stabilizer, was used as a conductor sample. The measurement results indicate that the ramp rate at the conductor excitation and the one-time thermal cycle of the conductor do not affect the self-fields but the voltages.

The current center position in the conductor cross-section during the conductor excitation was analyzed from the measurement results of the self-fields. The current center position always maintains the same position in the middle of the cross-section during the excitation. The analysis indicates that the current distribution of the STARS conductor is stable during the excitation. In addition, two-dimensional magnetic field calculations were conducted using the various models for the cross-sectional configuration of the STARS conductor. As a result, the calculation results agree with the measurement results regarding the self-fields.
\end{abstract}

\section{Keywords:}

Magnetic field measurement, voltage measurement, REBCO tape, current distribution, Magnetic field calculation, Stacked tapes assembled in rigid structure (STARS) conductor

\section{Introduction}

In order to realize a higher magnetic field of fusion magnets and accelerator magnets, various large current-carrying conductors composed of high temperature superconducting (HTS) tapes have recently been proposed [1-8]. In the National Institute for Fusion Science, the HTS 
conductor which is called, "stacked tapes assembled in rigid structure (STARS)" conductor, is being developed for the fusion reactor based on the large helical device [7-10]. The STARS conductor has arrays of simply stacked REBCO tapes embedded in a copper stabilizer and an outer stainless steel (SUS) jacket. In this study, the measurements of self-fields and voltages for the STARS conductor were conducted to investigate the current distribution of the STARS conductor. The conductor sample is composed of 45 REBCO tapes whose length is approximately $3 \mathrm{~m}$ and is in a straight shape. In addition, magnetic field calculations were conducted by modeling the STARS conductor cross-section, and the calculation results were compared with the measurement results regarding the self-fields.

\section{Conductor sample}

The conductor sample is composed of the STARS conductor, the cross-section of which is shown in Fig. 1. In the conductor, the cable composed of 45 ( 15 tapes $\times 3$ rows) REBCO tapes is covered with a copper jacket the material of which is $\mathrm{C} 1100$. The details of the REBCO tape are listed in Table 1. Indium sheets are inserted between the cable and the copper jacket. And the copper jacket is covered with a SUS jacket the material of which is SUS304. Fig. 2 shows the schematic view of the conductor sample. The configuration of the sample is straight, and the total length of the sample is $3200 \mathrm{~mm}$. At the terminal, the cable and the copper shim were connected through indium sheets so that all of the REBCO tapes were in contact with the copper shim. The schematic view of the terminal is illustrated in Fig. 3.

\section{Experimental setup}

The conductor sample was set in a vessel, and the energization tests of the sample was conducted while cooling the sample with liquid nitrogen $\left(\mathrm{LN}_{2}\right)$. The terminals of the sample were connected to a DC power supply. In the tests, the sample voltage was measured with the voltage taps located at the conductor ends as shown in Fig. 2. The length between the voltage taps was $2700 \mathrm{~mm}$. Hall sensors were arranged on the sample to measure self-fields generated by the sample, and the position of the sensors was at the middle of the sample in the longitudinal direction. Self-fields in the $x$-direction were measured with the Hall sensors. Fig. 4 illustrates the layout of five Hall sensors B1, B2, B3, B4, and B5 with the cross-section of the conductor sample. The model reference of the Hall sensors is F.W. BELL. BHT 921.

\section{Measurements}




\subsection{Energization tests with trapezoidal current waveforms}

When the conductor sample was energized with two different trapezoidal current waveforms, self-fields and total voltage of the conductor sample were measured using the Hall sensors and the voltage tapes, respectively. Fig. 5 shows the measurement results in the case that the conductor sample was energized up to $4000 \mathrm{~A}$ with the ramp rate of $400 \mathrm{~A} / \mathrm{s}$, and was degaussed with the ramp rate of $400 \mathrm{~A} / \mathrm{s}$ after holding $4000 \mathrm{~A}$ for $120 \mathrm{sec}$. The self-fields were always proportional to the sample current during the energization. The voltage increased rapidly up to about $0.7 \mathrm{mV}$ at the excitation of the sample conductor, and was kept at $0.7 \mathrm{mV}$ while holding $4000 \mathrm{~A}$. The voltage of $0.7 \mathrm{mV}$ is slightly larger than $0.27 \mathrm{mV}$ derived from the critical current (Ic) criterion of $1 \times 10^{-4} \mathrm{~V} / \mathrm{m}$.

Fig. 6 shows the measurement results with the other trapezoidal current waveforms. In this measurement, the conductor sample was energized up to $4500 \mathrm{~A}$ with the ramp rate of 100 $\mathrm{A} / \mathrm{s}$, and was degaussed with the ramp rate of $100 \mathrm{~A} / \mathrm{s}$ after holding $4500 \mathrm{~A}$ for $10 \mathrm{sec}$. The self-fields were proportional to the sample current and always stable during the energization. On the contrary, the voltage increased sharply after the current exceeded approximately $4000 \mathrm{~A}$ during the conductor excitation. While holding the current of $4500 \mathrm{~A}$, the voltage was still increasing and finally reached to approximately $4 \mathrm{mV}$, which was about 15 times larger than the voltage criterion described above. As the cause of the continuous increase in voltage, it is considered that the heat generated by the flux-flow resistance of the conductor sample exceeded the cooling by liquid nitrogen, and as a result, the conductor's temperature continued to rise.

\subsection{Influence of current ramp rate at the excitation}

The self-fields and the total voltage of the conductor sample were measured at the excitation of the sample with different ramp rates. In the measurements, the conductor sample was energized up to $4500 \mathrm{~A}$, and the ramp rates were set as $100 \mathrm{~A} / \mathrm{s}$ and $500 \mathrm{~A} / \mathrm{s}$, respectively. Fig. 7 shows the measurement results of the self-fields and the voltages at each ramp rate. The self-fields at the ramp rate of $100 \mathrm{~A} / \mathrm{s}$ agree completely with those at the ramp rate of $500 \mathrm{~A} / \mathrm{s}$. Hence, the ramp rate of the excitation does not have an influence on the current distribution in the STARS conductor.

Regarding the voltages, there are slight differences at each ramp data. At the beginning of the excitation, the voltage at the ramp rate of $500 \mathrm{~A} / \mathrm{s}$ is larger than that at the ramp rate of $100 \mathrm{~A} / \mathrm{s}$ due to induced voltage. After that, as the conductor current increases, the voltage at the ramp rate of $500 \mathrm{~A} / \mathrm{s}$ increases while fluctuating. On the other hand, the voltage at the ramp rate of $100 \mathrm{~A} / \mathrm{s}$ increases smoothly. Finally, both voltages correspond at the current of $4500 \mathrm{~A}$. 


\subsection{Excitation of the conductor sample before/after thermal cycle}

To investigate the influence of a thermal cycling on the current distribution of the STARS conductor, self-field measurements of the conductor were conducted before and after the thermal cycling. In this measurement, the thermal cycling means warming a conductor sample that had been cooled with $\mathrm{LN}_{2}$ to room temperature and then cooling the conductor sample again with $\mathrm{LN}_{2}$. Fig. 8 shows the results of the self-field measurements before and after the thermal cycling for the conductor sample. The conductor sample was energized up to $4500 \mathrm{~A}$ with the ramp rate of $100 \mathrm{~A} / \mathrm{s}$. The self-fields before the thermal cycling were in good agreement with those after the thermal cycling. As a result, the measurement results indicate that the thermal cycling does not influence the current distribution of the STARS conductor.

Regarding the voltages of the conductor sample, the voltages were different before and after the thermal cycling when the conductor current reached approximately $4500 \mathrm{~A}$. The voltage after the thermal cycling was larger than the voltage before the thermal cycling, so that the conductor sample might be degraded due to the thermal stress from the thermal cycling.

\section{Discussion}

\subsection{Investigation of the current center position in the conductor cross-section}

The current center position in the STARS conductor was investigated from the self-fields measured in excitation tests in which the ramp rates of the conductor current are $100 \mathrm{~A} / \mathrm{s}$ and $500 \mathrm{~A} / \mathrm{s}$. To identify the current center position, a line current model composed of one line current with infinite length $[11,12]$ was used. The value of the one line current is equivalent to the transport current of the STARS conductor, and the positions $x$ and $y$ are used as a parameter for the current center position. The line current position was set as the position minimizing the sum of the squared self-field difference $\Delta B n$ between the measurement result $B_{n}$ and the calculation result $\mathrm{B}_{\mathrm{n}}{ }^{*}$ at each position of the five Hall sensors in the $x$-direction, which is

$$
\Delta B_{n}=B_{n}-B_{n}^{*}
$$

where $n$ is the number of the Hall sensors.

Figs. 9 and 10 show the position of the current center at the ramp rates of $100 \mathrm{~A} / \mathrm{s}$ and $500 \mathrm{~A} / \mathrm{s}$, respectively. In the case that the ramp rate is $100 \mathrm{~A} / \mathrm{s}$, the current centers at each time hardly move and are always located in the middle of the conductor cross-section. When the ramp rate is $500 \mathrm{~A} / \mathrm{s}$, the positions of the conductor center are almost the same as those of the current center at $100 \mathrm{~A} / \mathrm{s}$. As a result, the current distribution of the sample conductor is stable under the condition that the conductor is excited up to $4500 \mathrm{~A}$ with the ramp rate of either 100 $\mathrm{A} / \mathrm{s}$ or $500 \mathrm{~A} / \mathrm{s}$. 


\subsection{Comparison between the measurement and the calculation regarding the self-fields}

The self-field measurements were compared with the magnetic field calculation results under the condition that the conductor sample was energized at $4000 \mathrm{~A}$. In the calculations, two different models for the cross-sections of the conductor sample were used. One is a uniform current distribution in the stacked REBCO tapes simplifying the cross-sectional configuration. The other is an FEM model reproducing the stacked REBCO tapes in the conductor sample in details.

\subsubsection{The model simplifying the stacked REBCO tapes}

A two-dimensional magnetic field calculation was conducted analytically using the model simplifying stacked REBCO tapes composed of 15 sheets $\times 3$ rows, which is as shown in Fig. 1 , to a rectangular cross section whose configuration was $2 \mathrm{~mm}$ thickness $\times 12 \mathrm{~mm}$ width. In the rectangular cross-section, the current distribution was set as uniform. Fig. 11 shows the measurement and the calculation results of self-fields in the $x$-direction when the sample current is 4000 A. Regarding the measurements, the plots in Fig. 11 are the self-fields at $100 \mathrm{sec}$ in Fig. 5. The calculation results are the self-field distributions along the $x$ direction at $\mathrm{y}=17 \mathrm{~mm}$. As shown in Fig. 11, the measurements are in good agreement with the calculations in the middle region of the conductor cross-section which is from $-0.005 \mathrm{~m}$ to $0.005 \mathrm{~m}$ in the $x$-axis. However, there are slight differences between the measurement and the calculation except for the middle region.

\subsubsection{FEM model}

A two dimensional self-field of the sample conductor was calculated using the finite element method (FEM) software which is COMSOL Multiphysics 5.5 with AC/DC module [13]. In this calculation, the model is composed of an air region and stacked REBCO tapes assuming 45 REBCO tapes in three blocks, as illustrated in Fig. 12. The current distribution in the blocks is set as uniform. For the magnetic field calculation, the equation of a static magnetic field consisting of magnetic vector potential [14] is used:

$$
\nabla \times\left(\frac{1}{\mu} \nabla \times \boldsymbol{A}\right)=\boldsymbol{J}
$$

where $\boldsymbol{A}$ is magnetic vector potential, $\boldsymbol{J}$ is current density, and $\mu$ is permeability. Regarding the boundary condition of the calculation, Neuman boundary condition was used on the perimeter of the air region. Fig. 13 shows the self-field distribution calculated by the FEM model when the transport current is $4000 \mathrm{~A}$. The maximum of the self-field is $0.226 \mathrm{~T}$ at the edge of the outer 
stacked tapes. Regarding the self-field in the $x$ direction at $\mathrm{y}=17 \mathrm{~mm}$, Fig. 14 shows the calculation result using the FEM model at $4000 \mathrm{~A}$, together with the measured result and the calculation result simplifying the stacked tapes. The calculation result agrees with the measured result, especially in the middle region of the conductor cross-section. Similar to the calculation result from the model simplifying the REBCO tapes as shown in Fig. 11, there is a small difference between the measured result and the calculation result from the FEM model except for the middle region.

\subsubsection{FEM model including E-J characteristics}

To investigate the influence of the REBCO tape's E-J characteristics on the self-fields generated by the conductor sample, the FEM model described in Section 5.2.2. was improved and the self-field was recalculated. In this calculation, the H-formulation including the E-J power law of the REBCO tapes [15-21] was used. The H-formulation is composed of the following equations [19]:

$$
\begin{aligned}
& \nabla \times \boldsymbol{H}=\boldsymbol{J} \\
& \nabla \times \boldsymbol{E}=-\frac{\partial \boldsymbol{B}}{\partial t} \\
& \boldsymbol{B}=\mu \boldsymbol{H} \\
& \boldsymbol{E}=\rho \boldsymbol{J} \\
& E=E_{c}\left(\frac{J}{J_{c}}\right)^{n}
\end{aligned}
$$

where $\boldsymbol{H}$ is the magnetic field intensity, $\boldsymbol{J}$ is the current density, $\boldsymbol{E}$ is the electric field, $\boldsymbol{B}$ is the magnetic flux density, $\mu$ is the permeability, $\rho$ is the resistivity, $E_{c}$ is the critical electric field, $J_{c}$ is the critical current, and $n$ is the $n$-value.

Regarding the characteristics of the REBCO tapes, the parameters are set as follows: $J_{c}$ is $160 \mathrm{~A} / \mathrm{mm}^{2}$ and $n$-value is 30 . In this model, the magnetic field dependence of $J_{c}$ is not considered. The model configuration and the boundary condition of this calculation is the same as those of the calculation described in the Section 5.2.2. The H-formulation includes the time-dependent equation which is Eq. 4, so that the self-field was calculated from the transport current $0 \mathrm{~A}$ to $4000 \mathrm{~A}$ at the ramp-rate of $100 \mathrm{~A} / \mathrm{s}$. Fig. 15 shows the calculation results of the self-field distribution generated by the FEM model with the E-J characteristic when the transport current is $4000 \mathrm{~A}$. The self-field distribution of the FEM model with the E-J characteristics is almost the same as that of the FEM model without the E-J characteristic. Regarding the self-fields in the $x$ direction on the axis where the Hall sensors are arranged, Fig. 
16 shows the calculation result of the FEM model with the measurement result and the calculation results of the other models when the transport current is $4000 \mathrm{~A}$. The calculation result of the FEM model with the E-J characteristics agrees with the measurement result and is in good agreement with the other calculation results. As a result, the E-J characteristics of the HTS does not have an influence on the self-field of the conductor sample.

Through the calculation results described in Section 5.2, the calculation results agree fairly with the measurements in the middle of the conductor cross-section, but there is a slight difference between the calculation and the measurement except for the middle region. As a cause of the difference, it is considered that the arrangement of the REBCO tapes in the conductor cross-section shown in Fig. 1 may be different from the actual arrangement. In the future, it is necessary to cut the sample conductor and confirm the placement of the stacked REBCO tapes inside the conductor cross-section.

\section{Conclusion}

The measurements of self-fields and voltages for the STARS conductor immersed in $\mathrm{LN}_{2}$ were conducted when the conductor was energized under various conditions. As a result, the self-fields were not influenced by the variation of the ramp-rate for the excitation and the one-time thermal cycle of the conductor. On the other hand, these events had an influence on the voltage of the conductor.

From the results of the self-field measurements, the current center position in the conductor cross-section was analyzed. The analysis indicates that the current center always keeps the same position in the middle of the cross-section during the conductor excitation. Hence, the current distribution in the conductor cross-section is considered stable at the excitation.

Two-dimensional magnetic field calculations were conducted using various models for the STARS conductor, and the calculation results were compared with the measurements regarding the self-fields. The calculation results agreed with the measurement results, provided that there was slight difference between the calculation and the measurement except for the middle region of the conductor cross-section. The misalignment of the stacked HTS tapes inside the conductor is considered as a cause of the difference.

\section{Acknowledgments}

The authors would like to thank Dr. Y. Narushima, Dr. N. Hirano, Dr. Y. Onodera of NIFS, and Mr. S. Matsunaga of SOKENDAI for their technical support. 


\section{References}

[1] M. Takayasu, L. Chiesa, L. Bromberg, J. Minervini, HTS twisted stacked-tape cable conductor, Supercond. Sci. Technol. 25 (2012) 014011.

[2] D C van der Laan, P D Noyes, G E Miller, H W Weijers and G P Willering, Characterization of a high-temperature superconducting conductor on round core cables in magnetic fields up to 20 T, Supercond. Sci. Technol. 26 (2013) 045005.

[3] W. Goldacker, F. Grilli, E. Pardo, A. Kario, S. Schlachter, Michal Vojenciak, Roebel cables from REBCO coated conductors: a one-century-old concept for the superconductivity of the future, Supercond. Sci. Technol. 27 (2014) 093001.

[4] D. Uglietti, R. Wesche, P. Bruzzone, Design and Strand Tests of a Fusion Cable Composed of Coated Conductor Tapes, IEEE Trans. Appl. Supercond., 24 (3) (2014) 4800704.

[5] G. Celentano, G. De Marzi, F. Fabbri, L. Muzzi, G. Tomassetti, A. Anemona, S. Chiarelli et al., Design of an Industrially Feasible Twisted-Stack HTS Cable-in-Conduit Conductor for Fusion Application, IEEE Trans. Appl. Supercond., 24 (3) (2014) 4601805.

[6] Y. Wang, S. Baasansuren, C. Xue, T. Hasegawa, Development of a Quasi-Isotropic Strand Stacked by 2G Wires, IEEE Trans. Appl. Supercond., 26 (4) (2016) 4804406.

[7] P. Bruzzone, W. H. Fietz, J. V. Minervini, M. Novikov, N. Yanagi et al., High temperature superconductors for fusion magnets, Nucl. Fusion 58 (2018) 103001.

[8] N. Yanagi, S. Ito, Y. Terazaki, Development of Large-Current High-Temperature Superconductors for Fusion Reactor Magnets -Present Status and Future Prospect-, TEION KOGAKU(J. Cryo. Super. Soc. Jpn.) 54 (1) (2019), 10-21. (in Japanese)

[9] Y. Terazaki, N. Yanagi, S. Ito, S. Hamaguchi, H. Tamura, H. Hashizume, Current-carrying capability of the $100 \mathrm{kA}$-class HTS STARS conductor for the helical fusion reactor FFHR-d1, IOP Conf. Series: Journal of Physics: Conf. Series 871 (2017) 012099

[10] N. Yanagi, Y. Terazaki, S. Ito, H. Tamura, S. Hamaguchi, H. Hashizume et al., Magnet design with 100-kA HTS STARS conductors for the helical fusion reactor, Cryogenics 80, (2016)243-249.

[11] T. Obana, K. Tahakata, S. Hamaguchi, S. Imagawa, T. Mito, K. Kizu, et al., Study on the dynamic behavior of a current in cable-in-conduit conductors by using self magnetic field measurements, Fusion Eng. Des. 86 (2011) 1377-1380.

[12] T. Obana, Y. Terazaki, N. Yanagi, S. Hamaguchi, H. Chikaraishi, M. Takayasu, Self-field measurements of an HTS twisted stacked-tape cable conductor, Cryogenics 105 (2020) 103012.

[13] COMSOL Multiphysics, https://www.comsol.jp/ 
[14] N. Takahashi, Finite element method of magnetic engineering, Asakura Publishing Co., Ltd. 2013 (in Japanese)

[15] Z. Hong, A Campbell and T. A Coombs, Numerical solution of critical state in superconductivity by finite element software, Supercond. Sci. Technol. 19 (2006) 1246-1252

[16] R. Brambilla, F. Grilli, L. Martini, Development of an edge-element model for AC loss computation of high-temperature superconductors, Supercond. Sci. Technol. 20 (2007) 16-24.

[17] V. Rodriguez-Zermeno, N. Mijatovic, C. Traeholt, T. Zirngibl, E. Seiler et al., Towards Faster FEM Simulation of Thin Film Superconductors: A Multiscale Approach, Appl. Supercond., 21(2011) 3273-3276.

[18] L. Queval, V. Zermeno and F. Grilli, Numerical models for ac loss calculation in large-scale applications of HTS coated conductors, Supercond. Sci. Technol. 29 (2016) 024007.

[19] B. Shen, J. Li, J. Geng, L. Fu, X. Zhang et al., Investigation of AC losses in horizontally parallel HTS tapes, Supercond. Sci. Technol. 30 (2017) 075006.

[20] B. Shen, J. Li, J. Geng, L. Fu, X. Zhang et al., Investigation and comparison of AC losses on stabilizer-free and copper stabilizer HTS tapes, Physica C: Supercond. and its appl. 541 (2017) 40-44.

[21] C. Kan, Y. Wang, X. Yuan, Y. Li, Y. Hou, AC Loss Analysis on a Quasi-Isotropic Strand Stacked by $2 \mathrm{G}$ Wires by Numerical Simulation in Cryogenic Temperature, IEEE Trans. Appl. Supercond., 28 (3) (2018) 8200206

Table 1 Details of REBCO tape.

\begin{tabular}{ll}
\hline \hline Model number & Fujikura FESC-SCH04 \\
Width & $4 \mathrm{~mm}$ \\
Substrate material & Nickel-based alloy \\
Thickness of substrate & $50 \mu \mathrm{m}$ \\
Surround copper layer & $20 \mu \mathrm{m}$ per side \\
Minimum Ic at 77 K, s.f ${ }^{\text {a }}$ & $85 \mathrm{~A}$ \\
\hline \hline
\end{tabular}




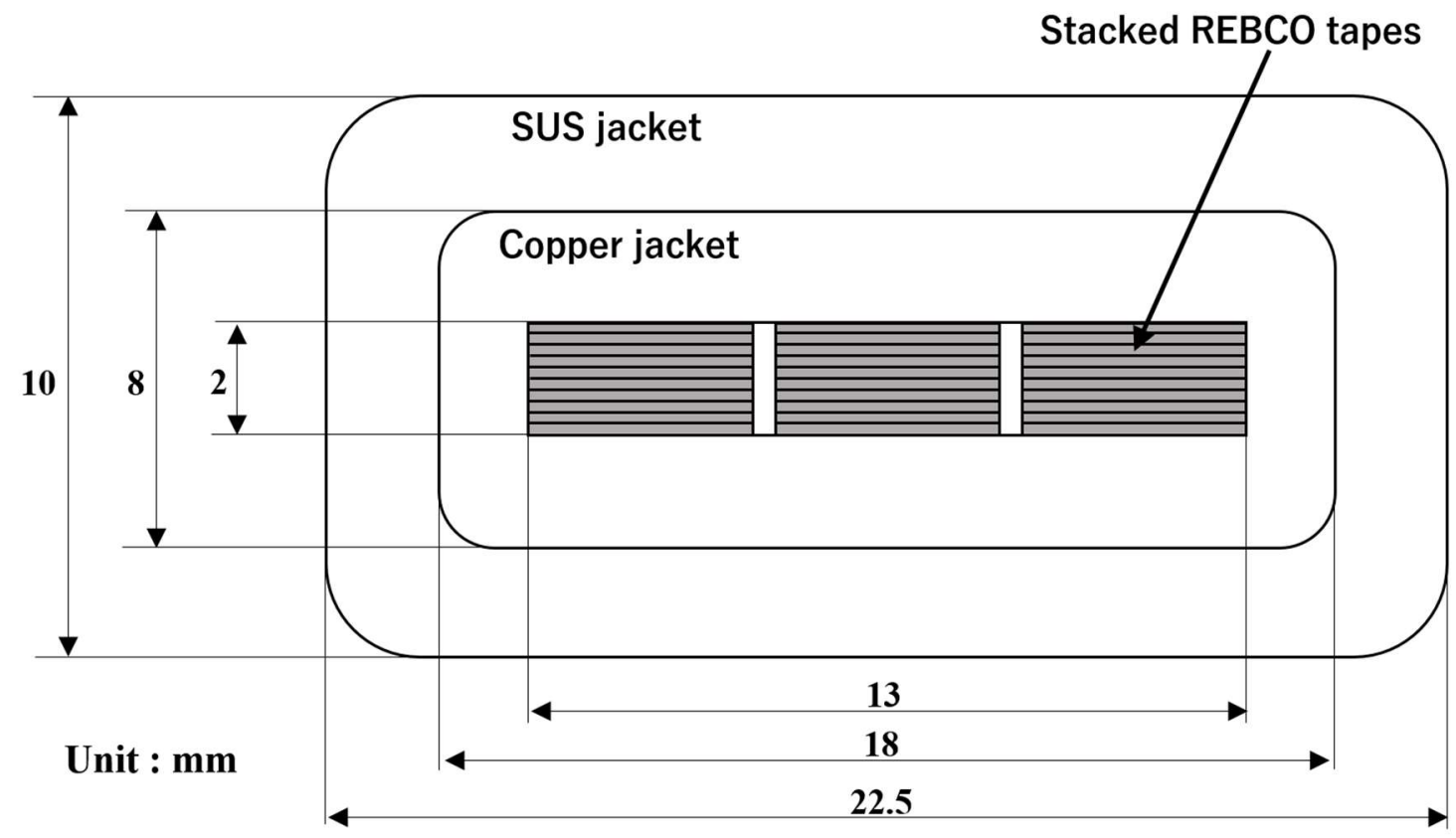

Fig. 1 The cross-section of the STARS conductor sample. The gaps between stacked REBCO tapes are $0.5 \mathrm{~mm}$ each.

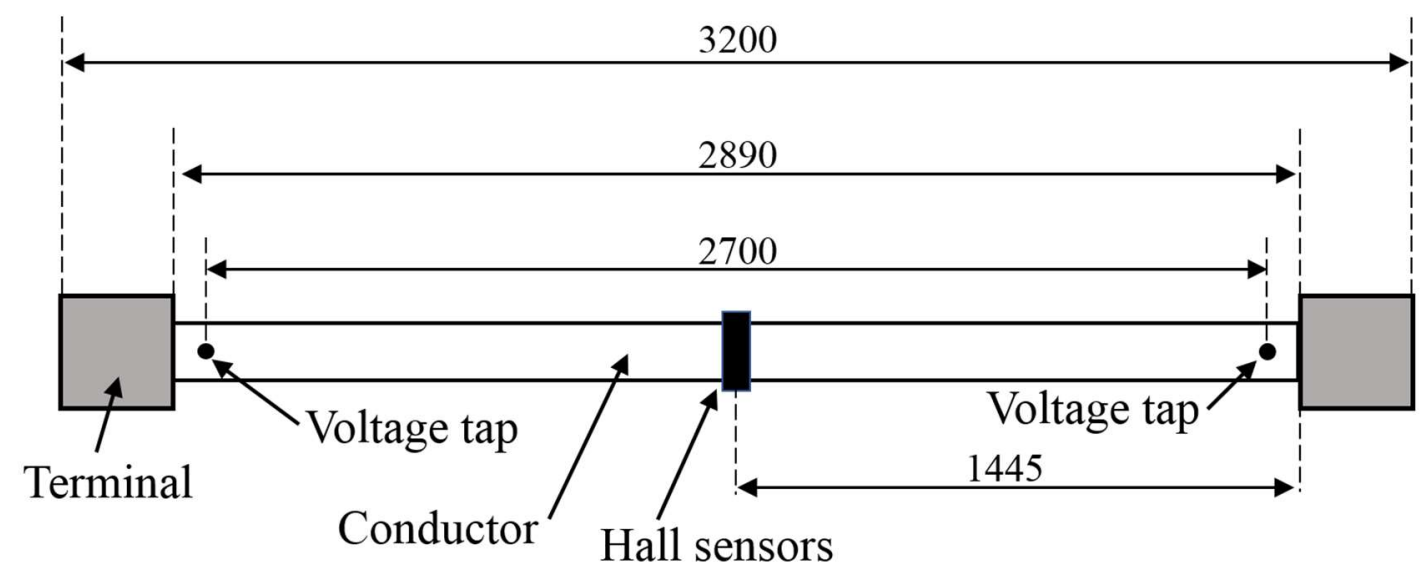

Unit: mm

Fig. 2 The schematic view of the STARS conductor sample from the top view. 


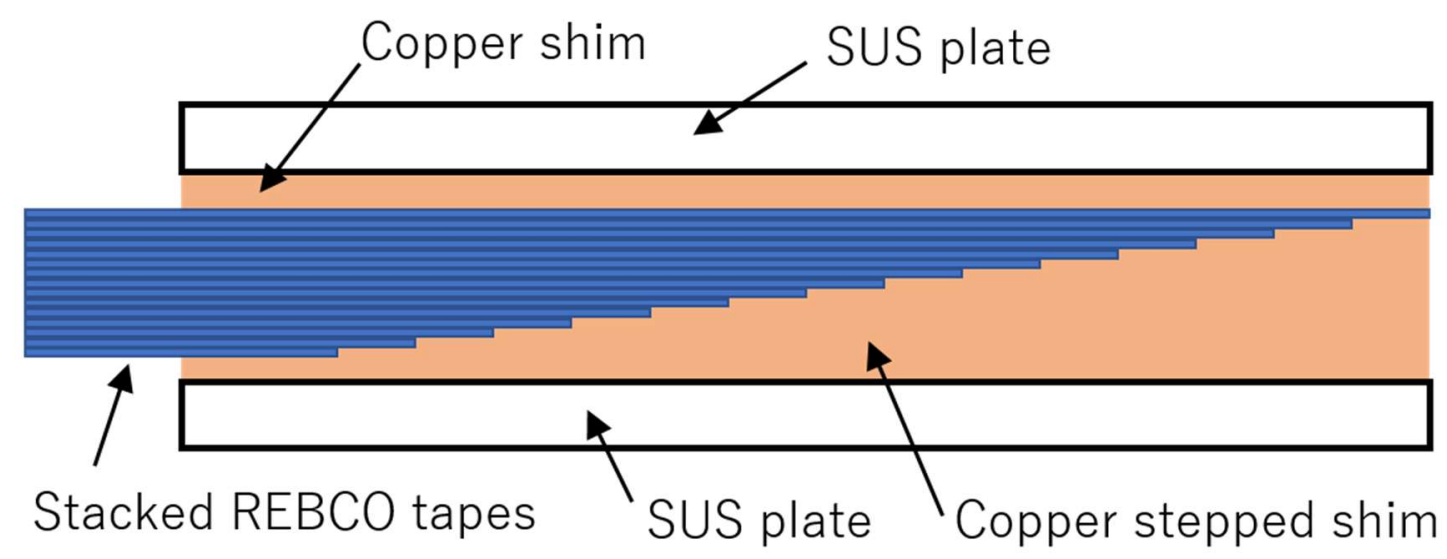

Fig. 3 The schematic view of the terminal in the conductor sample from the side view.

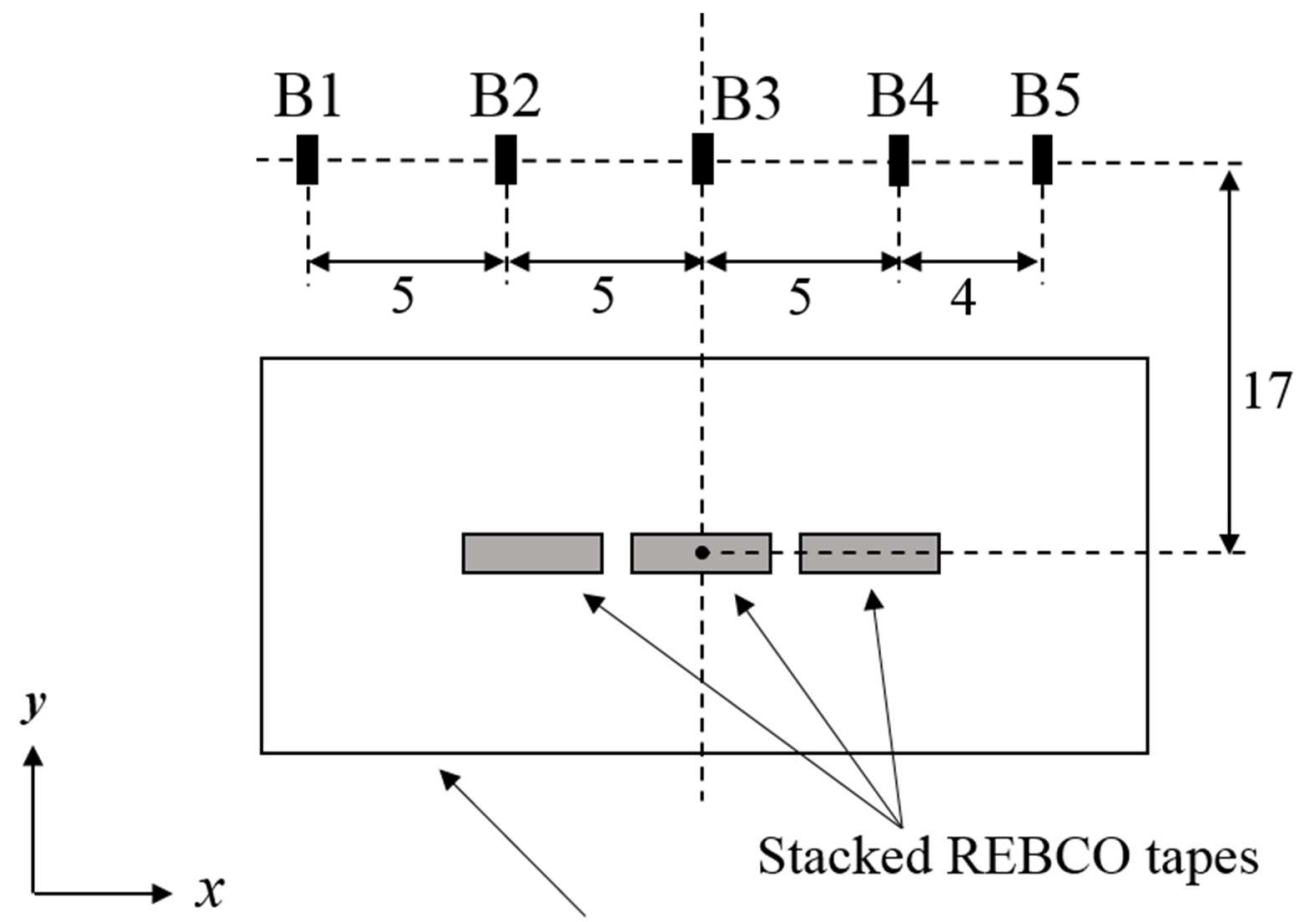

Unit: $\mathbf{m m} \quad$ Perimeter of the SUS jacket

Fig. 4 The layout of Hall sensors with the cross-section of the STARS conductor sample. 


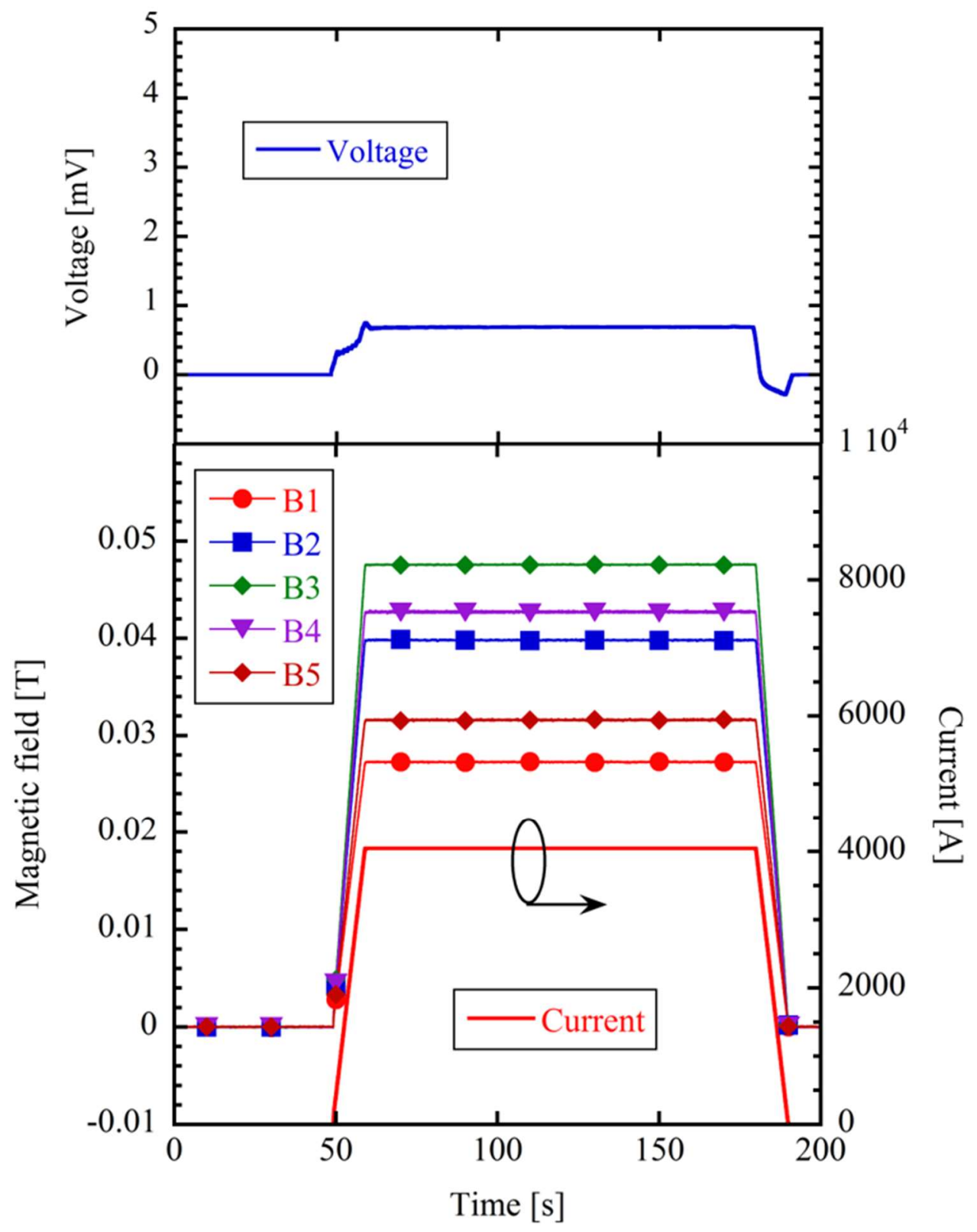

Fig. 5 The measurement results of the self-field and the voltage of the conductor sample at the trapezoidal current waveform whose maximum current is $4000 \mathrm{~A}$. 


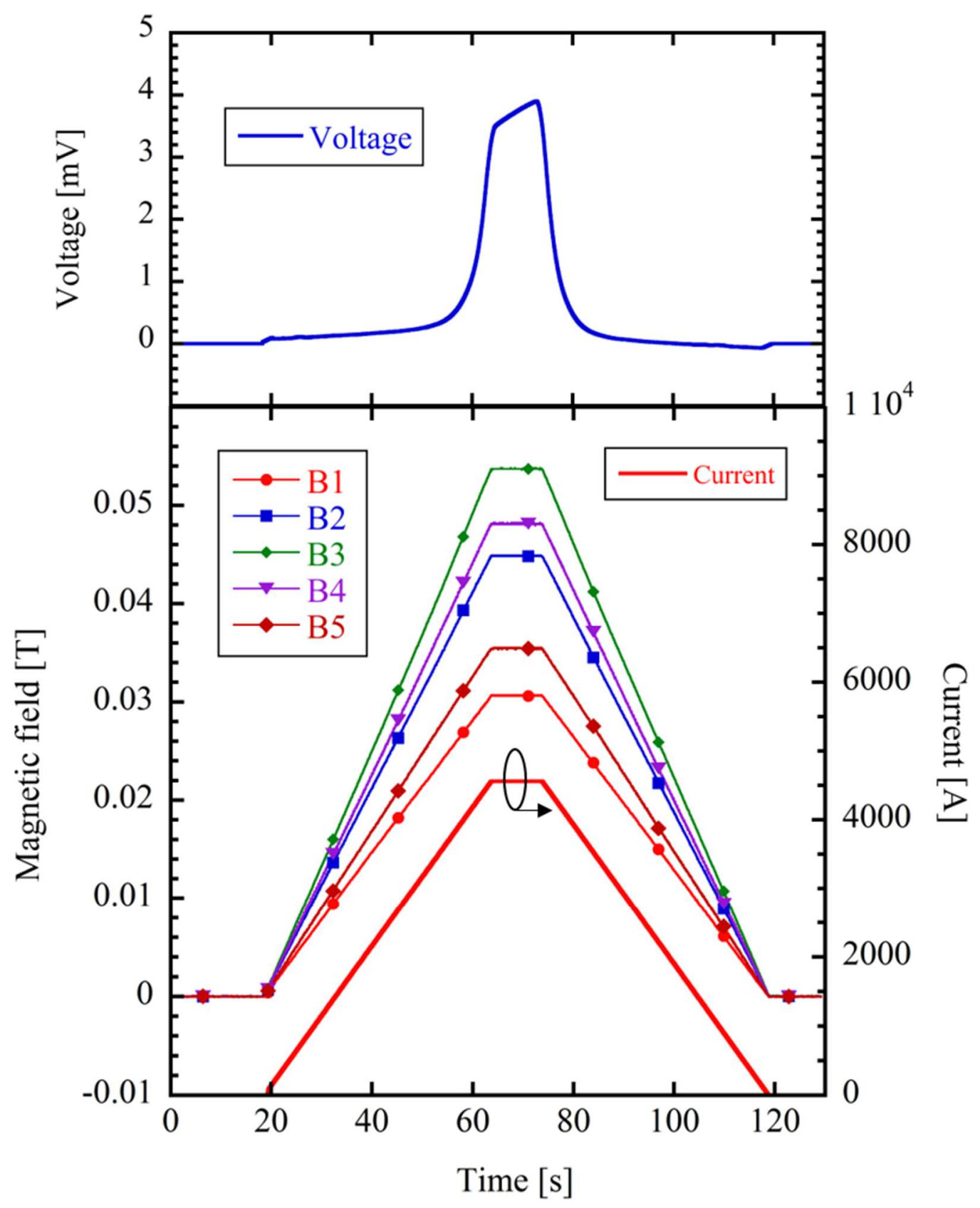

Fig. 6 The measurement results of the self-field and the voltage of the conductor sample at the trapezoidal current waveform whose maximum current is $4500 \mathrm{~A}$. 


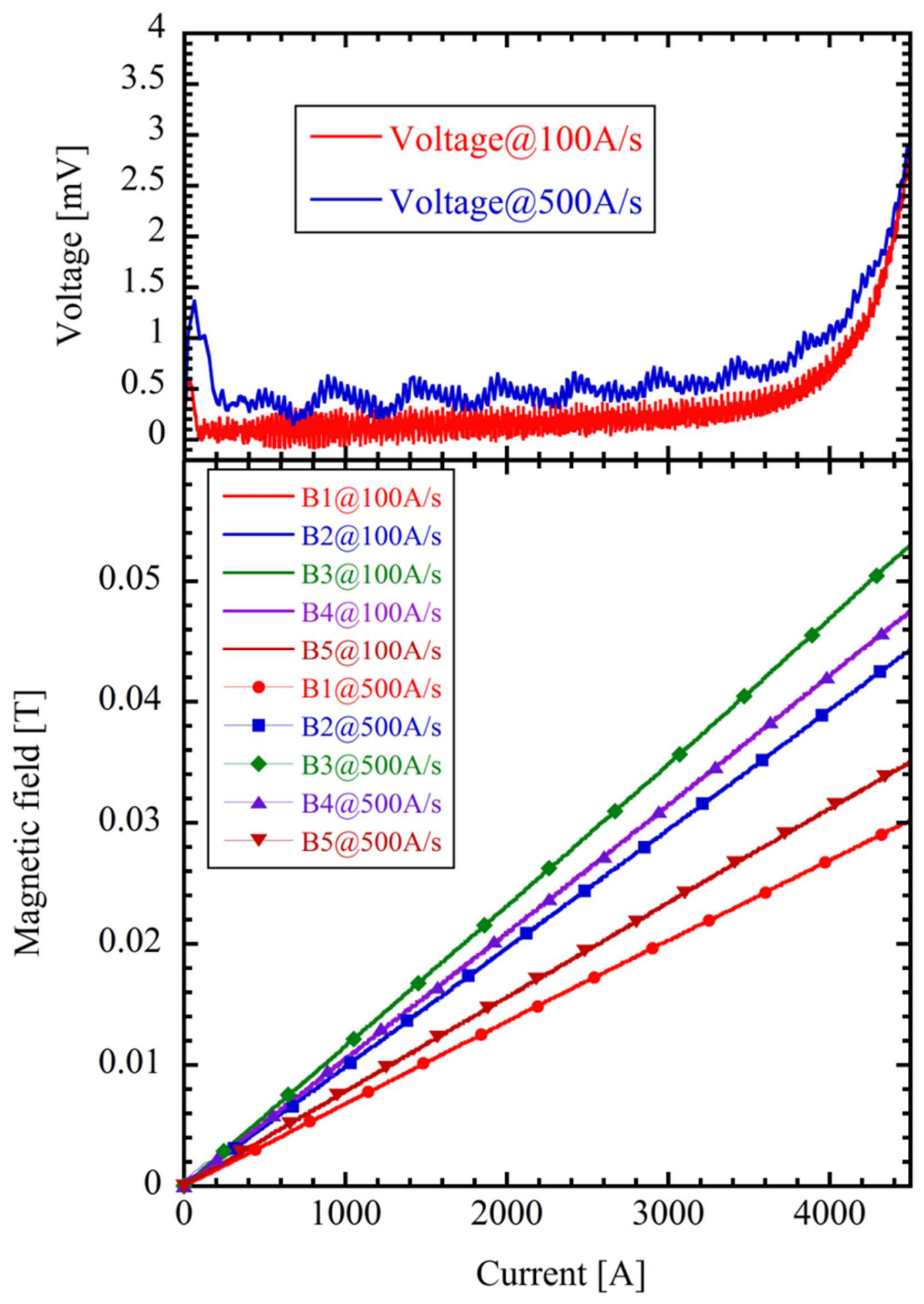

Fig. 7 The measurement results of the self-field and the voltage of the conductor sample at the excitation with the ramp rates of $100 \mathrm{~A} / \mathrm{s}$ and $500 \mathrm{~A} / \mathrm{s}$. 


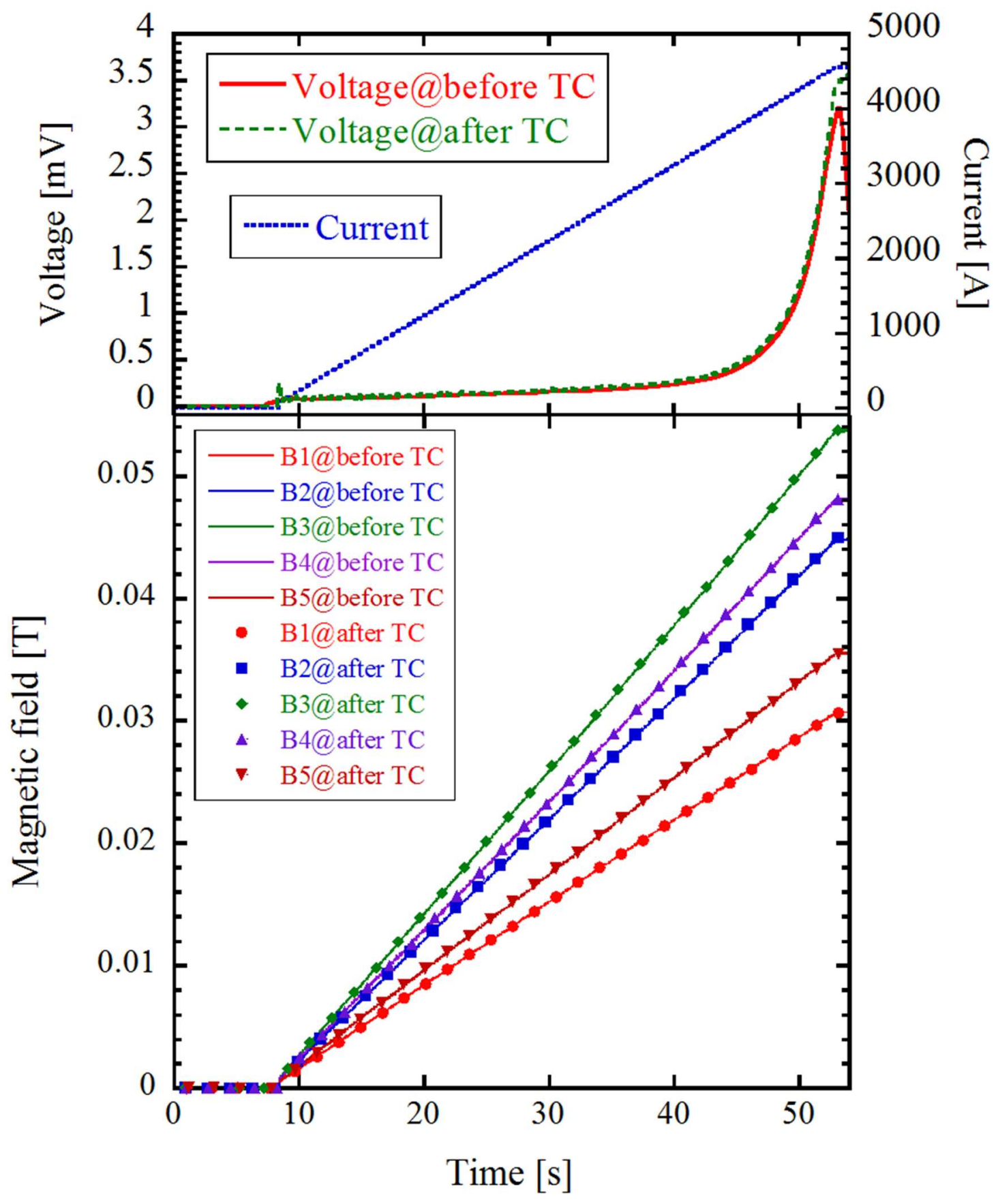

Fig. 8 The measurement results of the self-field and the voltage of the conductor sample before and after the thermal cycling. 


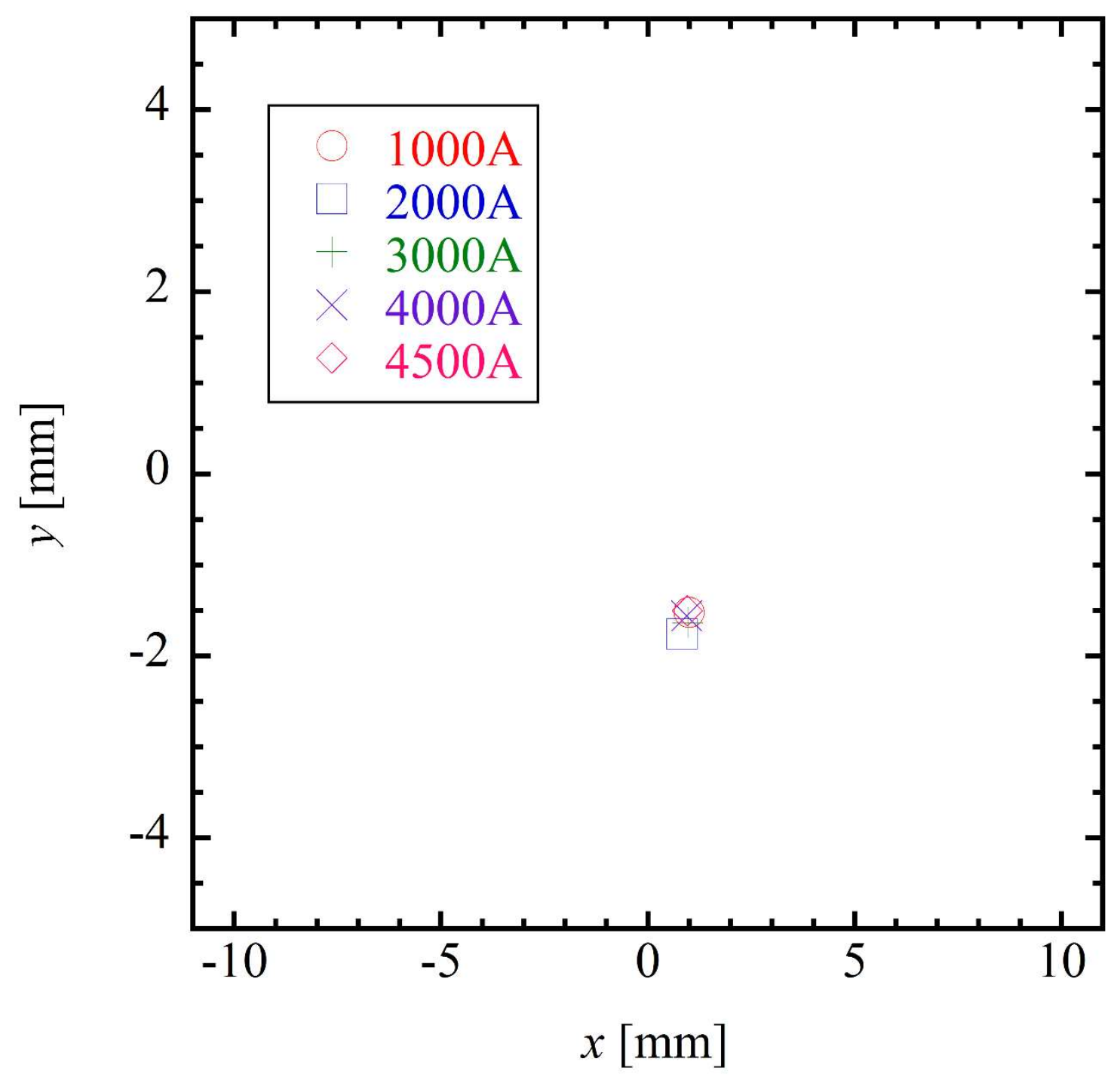

Fig. 9 The position of the current center in the conductor sample at the ramp rate of $100 \mathrm{~A} / \mathrm{s}$. The lengths of the $\mathrm{x}$-axis and $\mathrm{y}$-axis in this figure matches the conductor cross-sectional size $(22.5 \mathrm{~mm} \times 10 \mathrm{~mm})$. 


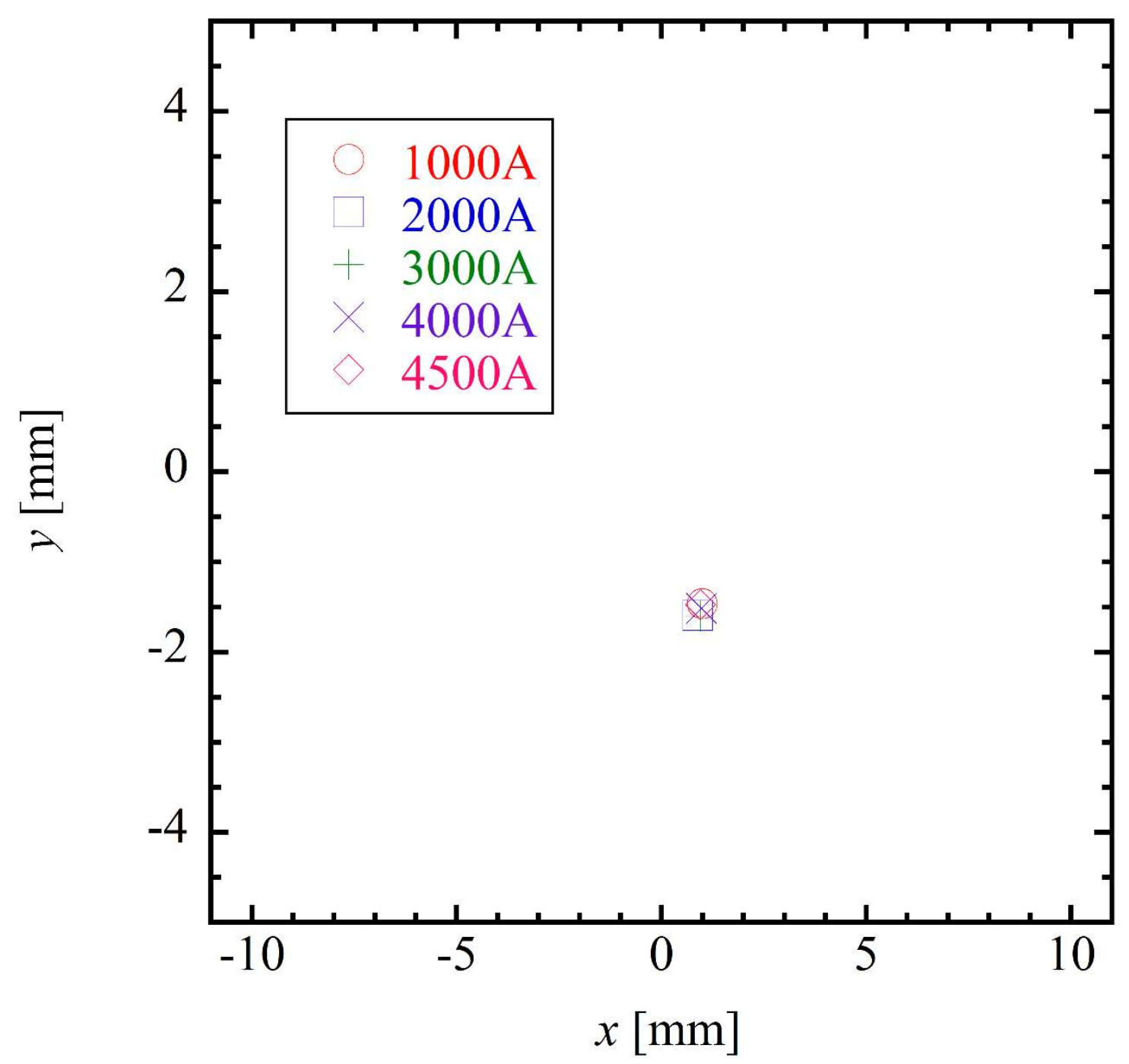

Fig. 10 The position of the current center in the conductor sample at the ramp rate of $500 \mathrm{~A} / \mathrm{s}$. The lengths of the $\mathrm{x}$-axis and $\mathrm{y}$-axis in this figure matches the conductor cross`sectional size $(22.5 \mathrm{~mm} \times 10 \mathrm{~mm})$. 


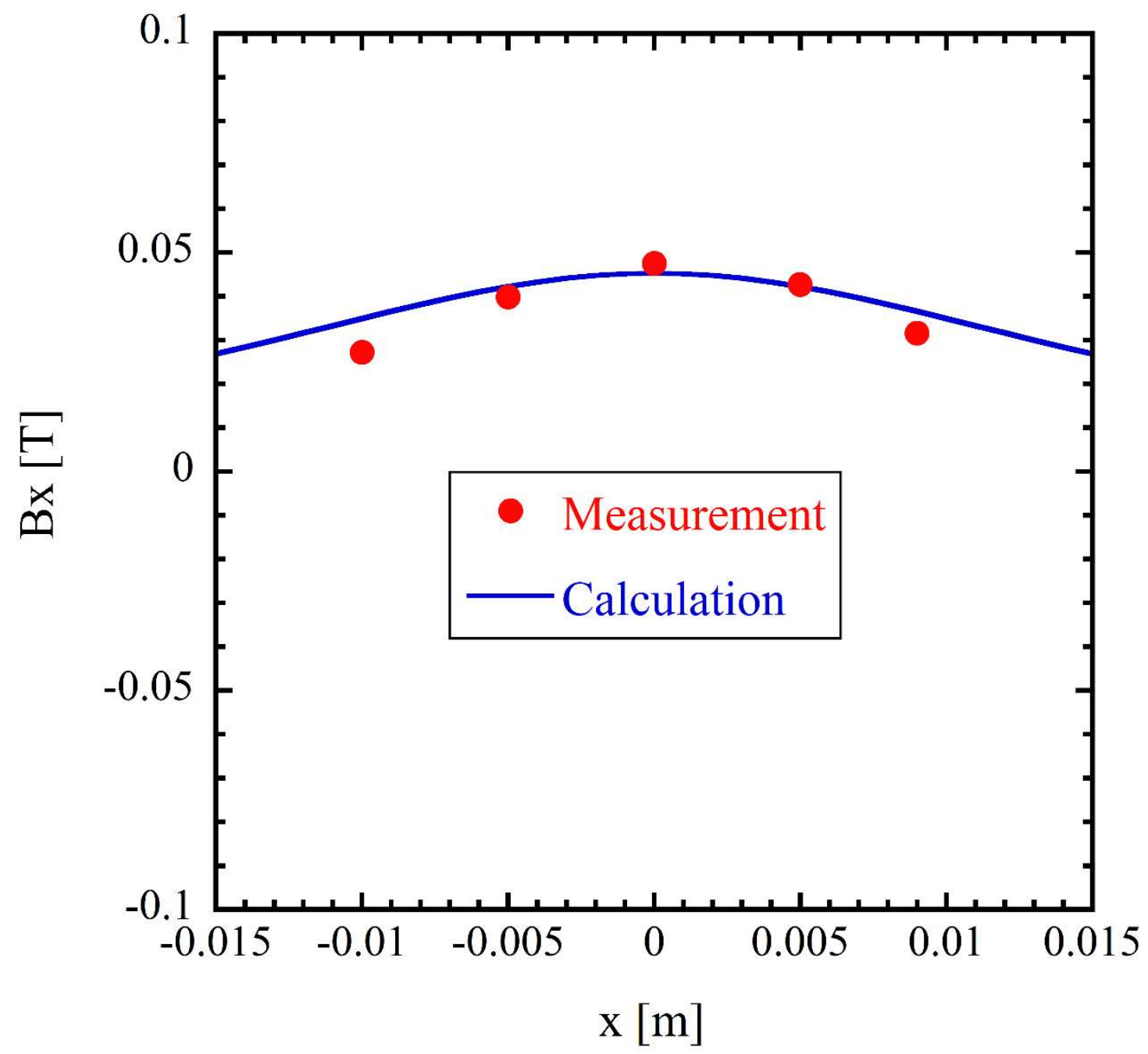

Fig. 11 Comparison between the measurement result and the calculation result for self-fields of the conductor sample whose transport current is $4000 \mathrm{~A}$. 


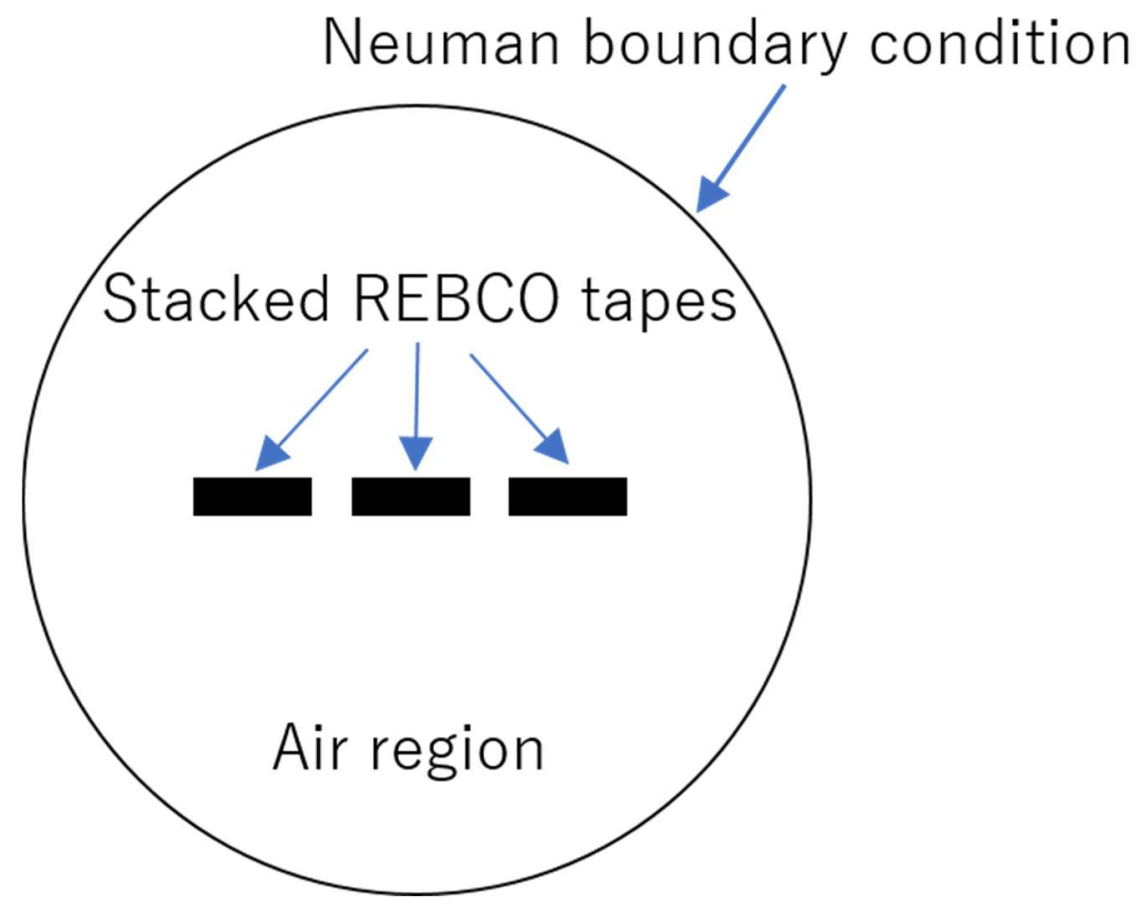

Fig. 12 The schematic view of the FEM model. 


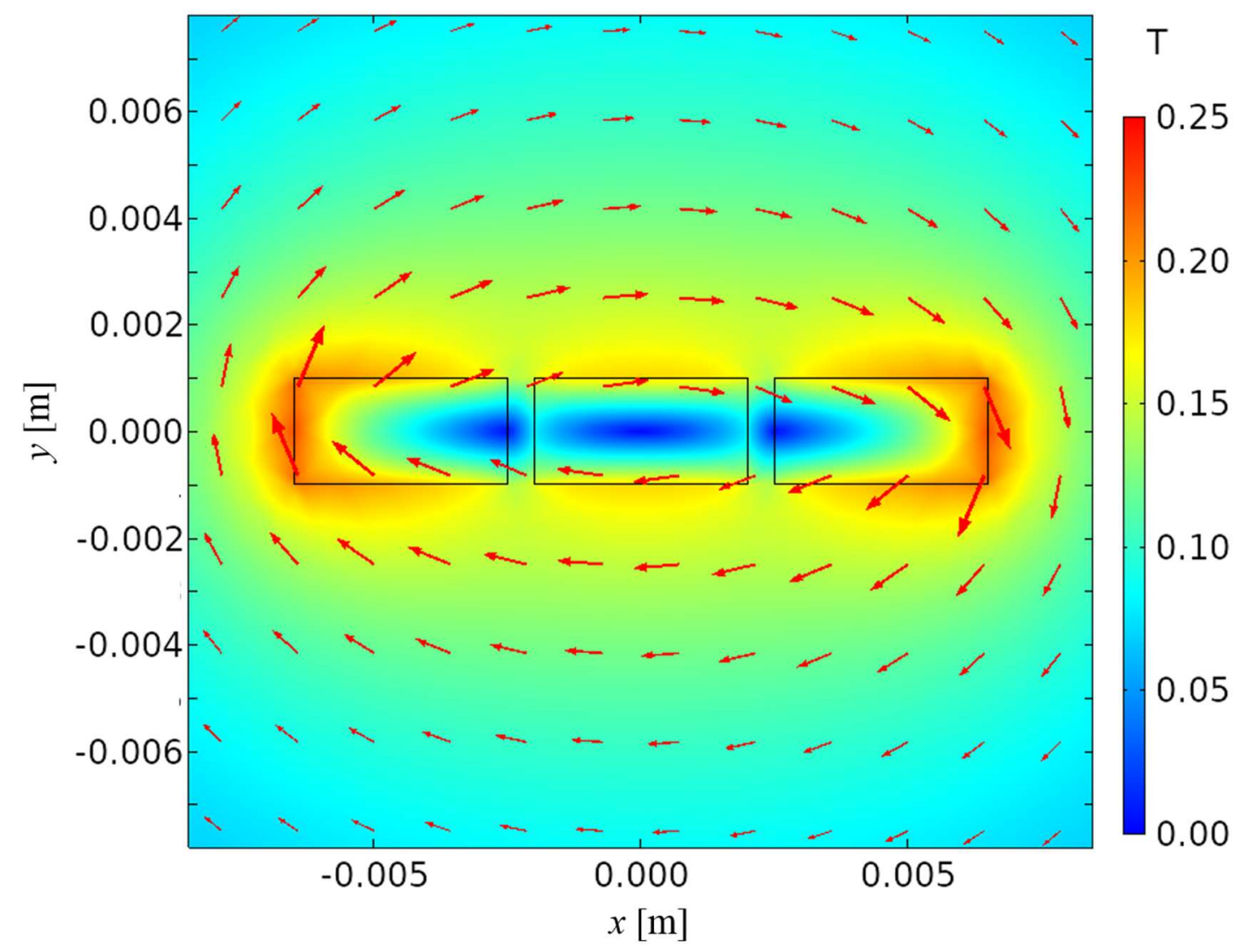

Fig. 13 The calculation result of the self-field distribution generated by the conductor sample using the FEM model. 


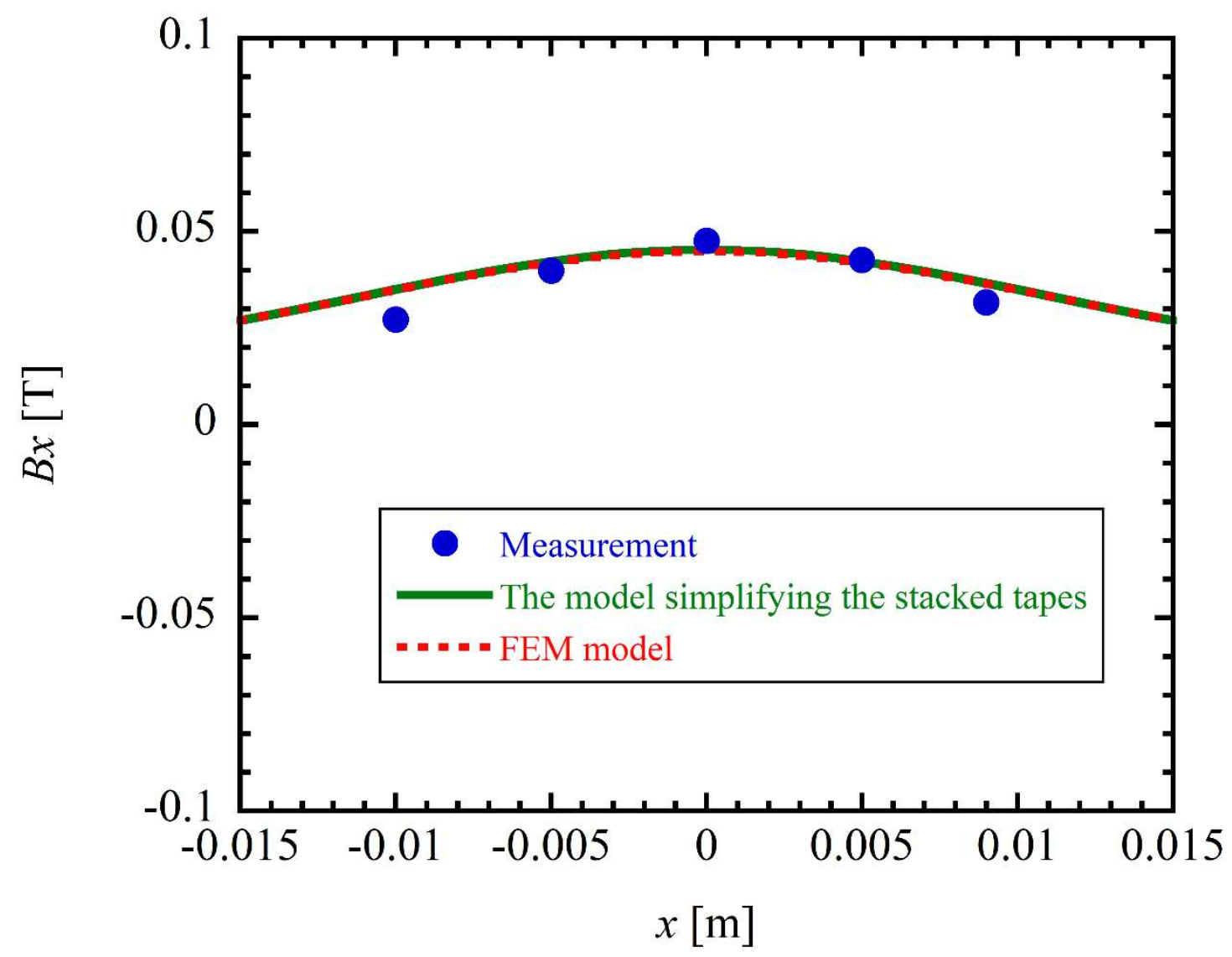

Fig. 14 Self-fields of the measurement result and the calculation results from the model simplifying the stacked tapes and the FEM model. 


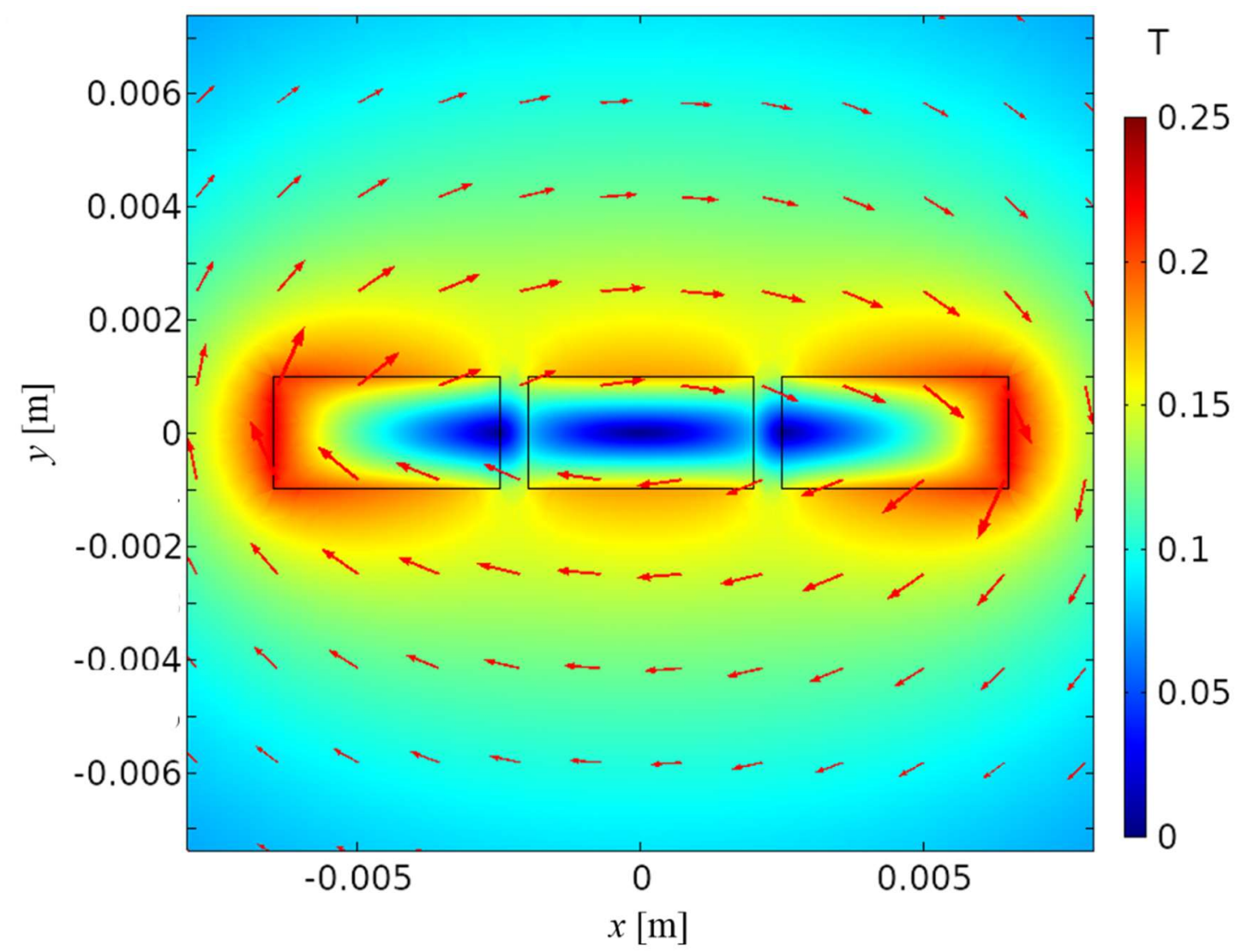

Fig. 15 The calculation result of the self-field distribution generated by the conductor sample using the FEM model with the E-J characteristics when the transport current is $4000 \mathrm{~A}$. 


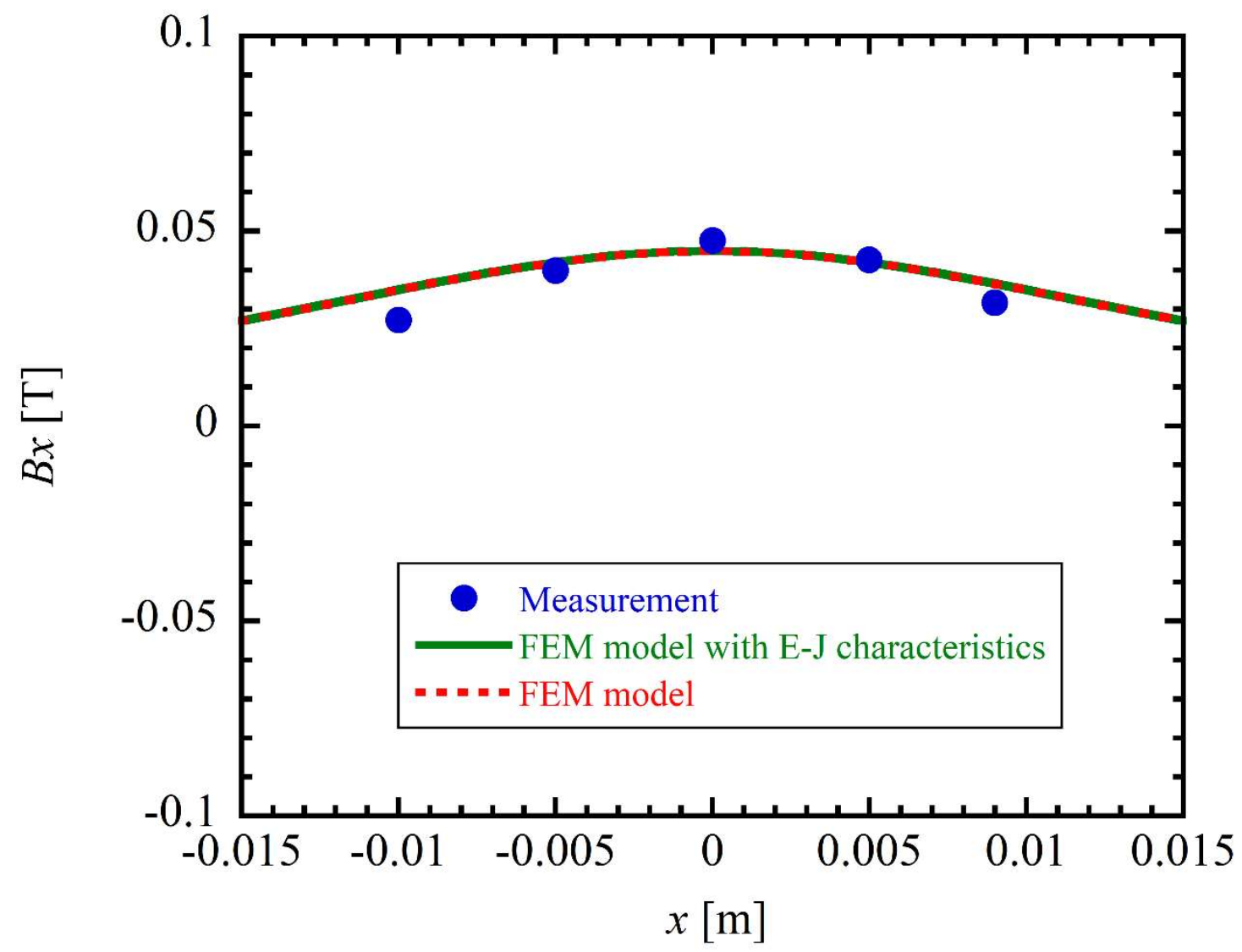

Fig. 16 Self-fields of the measurement result and the calculation results from the FEM models w/ and w/o the E-J characteristics. 